\title{
Looking back, looking forward
}

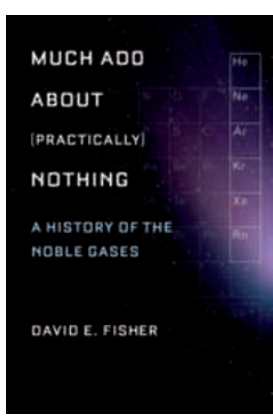

Much ado about (practically) nothing: A history of the noble gases by David E. Fisher

OXFORD UNIV. PRESS: 2010. 304 PP. $€ 15.99$

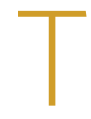
he noble gases are of great interest because of their unique physical properties, along with a remarkable set of radiogenic isotopes that provide timescales for terrestrial and solar system evolution. David Fisher is a recently retired professor of marine geology and geophysics, and prolific author of both fiction and non-fiction, whose research career combined geochemistry and planetary sciences. His book A History of the Noble Gases alternates between personal memoir and historical accounts of some key noble gas discoveries, thus combining his twin interests in story telling and research.

\section{The narrative emphasizes the} nonlinear progress of science, the difficulties in carrying out experiments, and the peril of
predicting the results

Fisher's stated intention is to provide the history of the noble gases in a "readable (that is, jargonless) manner" along with conveying the trials, tribulations and fun of doing science in American academic and national laboratory settings during a particular era. He succeeds. The historical vignettes are nicely told, and include Ernest Rutherford's work on nuclear structure, Kammerling Onnes's early work on liquid helium, and Ray Davis's famous solar neutrino experiment, among others. The book covers a wide range of topics that convey the incredible scope of noble gas research. Fisher finishes the book with a discussion of radon and some other interesting and surprising practical uses of noble gases, such as anaesthesia. He sprinkles his own opinions and humour freely, including quotations that range from Einstein to Buddha to Woody Allen, and gives literature references at the end of the book.

The narrative emphasizes the nonlinear progress of science, the difficulties in carrying out experiments, and the peril of predicting the results. In an era of dominance by applied research and 'targeted' societal relevance, it is crucial that scientists, citizens and policy makers remember how many discoveries have been serendipitous and unexpected.

Fisher's personal story follows an arc from Brookhaven National Laboratory to Cornell University and then to the University of Miami, where his research involved noble gas measurements in meteorites and ocean floor rocks. He describes personal difficulties relating to job hunting and tenure, along with some of the big scientific issues of the day, including the discovery of sea-floor spreading. This was a free-wheeling period in American science when the cold war fuelled copious funding. At one point Fisher describes his Department Chair walking the halls in search of takers for excess funds from a US funding agency, apparently without success because everyone was so wellfunded. Not a likely occurrence in today's research universities.

Fisher freely and humorously recounts his own persistent troubles as an experimentalist, including a high-voltage jolt across the room and a narrowly missed lab explosion. There are omissions and inaccuracies in the book. Fisher candidly characterizes some of his colleagues, with descriptors that range from 'gentleman' to 'son of a bitch', but does not always provide the details/justification. Despite an interest in attribution of credit for important discoveries, he sometimes paints the picture with too broad a brush. One example is the discovery of terrestrial primordial ${ }^{3} \mathrm{He}$ in 1969 , which is attributed to Harmon Craig in the West and Igor Tolstikhin in Russia. Brian Clarke is incorrectly given secondary credit only as a "student"; he was, in fact, the experimental mastermind who designed and built the mass spectrometer. Boris Mamyrin, the Russian physicist, is similarly omitted along with Alfred Nier, the father of modern mass spectrometry. It is probably unfair to point to such omissions in a story that covers so much territory, but any specialist will find their favourite gap, and the book would be more accurately entitled 'A personal history of the noble gases'.

\section{In an era of dominance by applied research, it is crucial to remember that many scientific discoveries have been serendipitous and unexpected}

Nevertheless, because of Fisher's skill as a storyteller, this book will be worthwhile reading for specialists, non-specialists, and the general public interested in the workings of science.

\section{REVIEWED BY MARK KURZ \\ Mark D. Kurz is in the Department of Marine Chemistry and Geochemistry, Woods Hole Oceanographic Institution, Woods Hole, Massachusetts 02543, USA.}

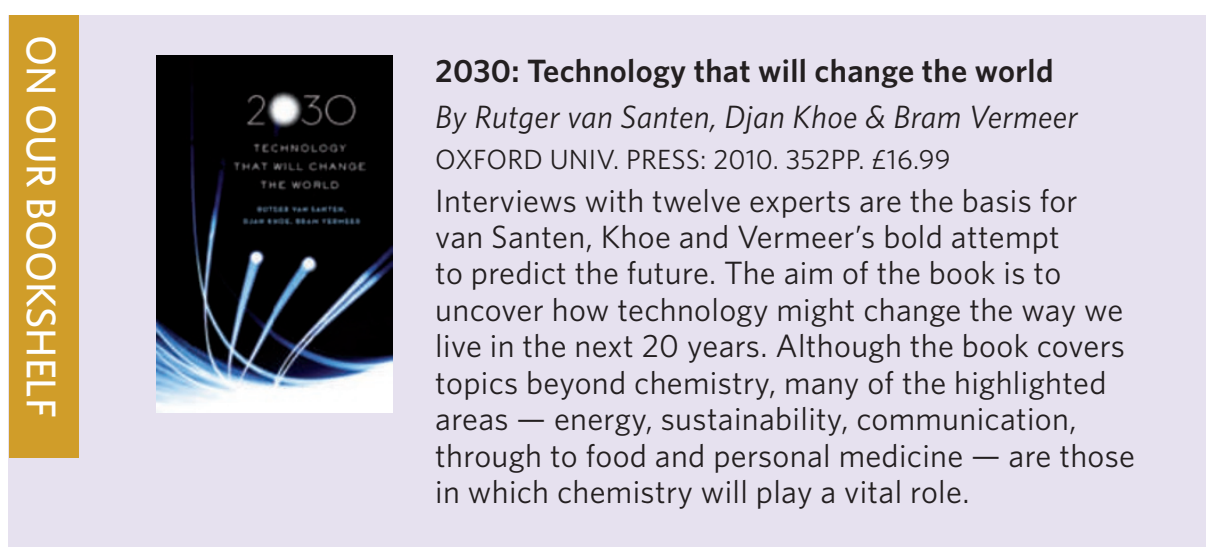

